\title{
Pneumatosis intracranialis: a rare association of cerebral air embolism and mesenteric ischemia
}

\author{
Pneumatose intracraniana: uma rara associação de embolismo gasoso cerebral e \\ isquemia mesentérica \\ Igor Gomes PADILHA ${ }^{1}$, Helena Alves Costa PEREIRA², Flávia Fajardo Linhares PEREIRA³, \\ Sérgio ZACHARIAS JUNIOR ${ }^{3}$, Antônio José da ROCHA ${ }^{1}$
}

A 67-year-old man presented with tetraparesis, which evolved rapidly into tetraplegia, and hyporeflexia and had decreased level of consciousness. Cranial and abdominal computed tomography (Figure 1) showed an intriguing association of mesenteric ischemia with pneumatosis intestinalis and intracranial air content in subarachnoid veins. This rarely reported association has been attributed to the ascension of air through the venous system when the central venous pressure is negative relative to the atmospheric pressure. It can trigger off a coagulation cascade resulting in impaired cerebral perfusion ${ }^{1,2}$. The term pneumatosis intracranialis is herein proposed to describe this imaging abnormality in association with the description of air content in the bowel wall.

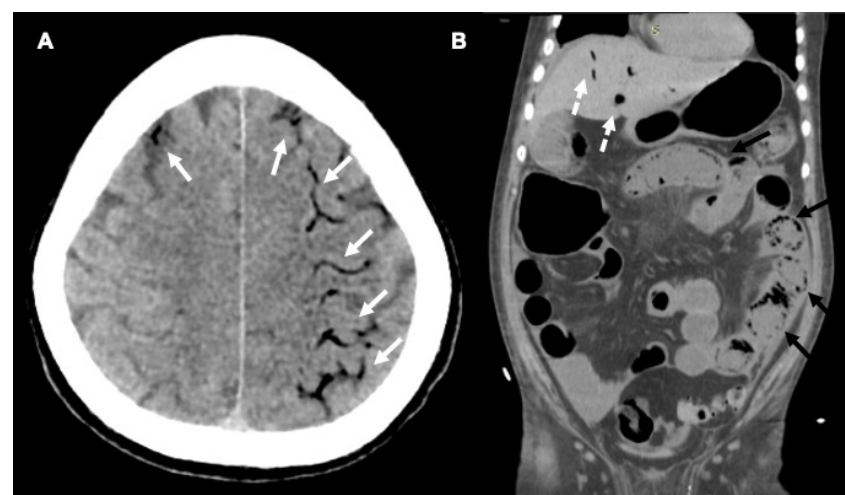

Figure 1. Pneumatosis intracranialis: a rare association of cerebral air embolism and mesenteric ischemia. Cranial computed tomography (CT) showed linear air content fulfilling the subarachnoid veins of frontoparietal convexity (pneumatosis intracranialis) probably related with intracranial distribution after venous ascension (white arrows in A). Abdominal CT was also performed, showing air content in the portal venous system (dashed white arrow in B) in addition to pneumatosis intestinalis (black arrows in B).
1. Spanuchart I, Tamura A, Matsuda B, Leo QJ, Sung H. Cerebral venous air embolism secondary to mesenteric infarction. Hawaii J Med Public Health. 2016 May;75(5):133-6.
2. Taydaș O, Onur MR, Akpınar E. Retrograde cerebral air embolism in a patient with intestinal necrosis: a case report. Balkan Med J. 2017 Aug;34(4):371-3. https://doi.org/10.4274/balkanmedj.2016.0292

'Santa Casa de São Paulo, Faculdade de Ciências Médicas, Departamento de Neuroradiologia, São Paulo SP, Brazil. ²Santa Casa de São Paulo, Faculdade de Ciências Médicas, Departamento de Imagem Torácica, São Paulo SP, Brazil. ${ }^{3}$ Hospital Risoleta Tolentino Neves, Departamento de Radiologia, Belo Horizonte MG, Brazil. IGP (iD) https://orcid.org/0000-0002-7639-0397; HACP (D) https://orcid.org/0000-0001-7331-8085; FFLP (D) https://orcid.org/0000-0002-2662-7093; SZJ (D) https://orcid.org/0000-0002-7304-8609; AJR (D) https://orcid.org/0000-0003-2591-9171

Correspondence: Igor Gomes Padilha; Email: igorpadilha_@hotmail.com.

Conflict of interest: There is no conflict of interest to declare.

Authors' contributions: IGP, HACP, FFLP, SZJ, AJR: design or conceptualization of the study, analysis or interpretation of the data, drafting or revising the manuscript for intellectual content.

Received on July 13, 2021; Received in its final form on July 18, 2021; Accepted on July 21, 2021. 